

\title{
A Utilização da Mídia Publicitária no Ensino de Geografia: Uma Oficina Pedagógica acerca da Discriminação da Mulher
}

\author{
La Utilización de los Medios de Comunicación Publicitaria en la Enseñanza de \\ Geografía: Un Taller Pedagógico a cerca de la Discriminación de la Mujer
}

\section{The Use of Advertising Media in Geography Education: A Pedagogical Workshop Focusing Women Discrimination}

\section{Resumo}

O presente artigo teve como principal objetivo investigar como a publicidade pode auxiliar na construção da discussão sobre a discriminação da mulher com alunos do ensino médio, e desta forma utilizá-la como uma ferramenta didática para a análise crítica de uma realidade social. Os resultados foram obtidos por intermédio de duas questões dissertativas respondidas pelos alunos e analisadas por meio do modelo de categorização elaborado por Fonseca (2015) que foi baseado na Análise de Conteúdo de Bardin (1977). Desta maneira, foi possível constatar a necessidade de se discutir com os educandos na disciplina de Geografia, a discriminação da mulher e atrelá-la ao conhecimento geográfico, para se construir a percepção de como esse problema se manifesta e se reproduz na sociedade.

Palavras-Chave: Discriminação da Mulher; Publicidade; Ensino de Geografia.

\section{Resumen}

El presente artículo tiene como principal objetivo investigar como la publicidad puede ayudar en la construcción de la discusión sobre la discriminación de la mujer con alumnos de enseñanza media, y de esta forma utilizarla como una herramienta didáctica para el análisis critico de una realidad social. Los resultados fueron obtenidos por medio de dos cuestionamientos expuestos en disertaciones en respuestas de los alumnos y analizadas por medio del modelo de categorización elaborado por Fonseca (2015) que se baso en el Análisis de Contenido de Bardin (1977). De esta manera, fue posible constatar la necesidad de discutir con los formados en la disciplina de Geografía, la discriminación de la mujer y atraerla al conocimiento geográfico, para construir la percepción de como ese problema se manifiesta y se reproduce en la sociedad.

Palabras-Clave: Discriminación de la Mujer; Publicidad; Enseñanza Geográfica.

\begin{abstract}
The main objective of this article was to understand how publicity can help the construction of a discussion about the discrimination of women with high school students, and in this way use it as a teaching tool for the critical analysis of a social reality. The results were obtained through two essay questions answered by the students and analyzed using the categorization model elaborated by Fonseca (2015), which was based on the Bardin Content Analysis (1977). In this way, it was possible to verify the need to discuss with the students in Geography classes, the discrimination of women and link it to geographic knowledge, in order to construct the perception of how this problem is manifested and reproduced in the society.
\end{abstract}

Keywords: Women Discrimination; Publicity; Geography Teaching. 
A Utilização da Mídia Publicitária no Ensino de Geografia: Uma Oficina

Pedagógica Acerca da Discriminação da Mulher

\section{A Geografia Feminista, a Discriminação da Mulher e sua Influência na Produção Espacial}

Sendo a Geografia a ciência social, cujo objeto de estudo é o espaço geográfico, torna-se necessário identificar como as relações sociais interferem na produção espacial e por isto, deve-se compreender o espaço como produto das mesmas. E entre estas relações, as de gênero não devem ser excluídas das análises da ciência geográfica, pois elas influenciam nas mais diversas escalas e processos econômicos, sociais e políticos (REIS, 2015).

A discriminação da mulher na sociedade tem se mostrado como um difícil desafio a se vencer, mesmo com os avanços em busca de maior equidade entre os gêneros nas últimas décadas, ainda são encontrados diariamente situações de discriminação e desrespeito com as mulheres. Por esta razão a escola pode atuar como um importante meio para que se possa efetivar uma educação realmente cidadã e que haja como instrumento de socialização dos saberes e de quebra de preconceitos e estereótipos negativos referentes aos gêneros.

Segundo Silva (1998, p. 107), gênero “(...) faz referência a todas as diferenças entre homens e mulheres que foram construídas social e culturalmente e que condicionam relações de subordinação/dominação." Assim, de acordo com senso comum gerado pela socialização, homens e mulheres possuem condutas distintas originadas naturalmente (instintos) que padronizam os comportamentos típicos de cada sexo.

Da mesma forma, para Joseli Maria Silva (2010, p. 40), gênero e sexo são "construções sociais permanentes que vão muito além de mera representação de papéis a serem desempenhados por corpos de homens e mulheres sob a hegemonia da heteronormatividade." Para a autora, gênero é uma falácia difundida no espaço pelos discursos hegemônicos.

Segundo Silva (1998) o movimento feminista ressurgiu no mundo ocidental nos anos de 1960 e 1970, devido ao nascimento de um sentimento de contestação da marginalização de grupos oprimidos. As mudanças ocorridas nesta época, como a entrada da mulher no mercado de trabalho e o avanço dos níveis de educação feminina também favoreceram o avanço do movimento e ressaltaram cada vez mais as relações desiguais entre gêneros em casa, no trabalho e na comunidade como um todo. (SILVA, 1998).

De acordo com Moreira (2015) a Geografia serve para desvendar as máscaras sociais por meio da análise do espaço geográfico (seu objeto de estudo). As relações sociais e as condições históricas interferem na produção espacial e por isto, é necessário compreender o espaço como produto das mesmas. E entre estas relações, as de gênero não devem ser excluídas das análises da ciência geográfica, pois elas influenciam nas mais diversas escalas e processos econômicos, sociais e políticos. (REIS, 2015).

Levando em consideração estes movimentos e entendendo que o espaço não é neutro do ponto de vista do gênero, Silva (1998) considera ser necessário incorporar e entender as diferenças sociais entre homens e mulheres nos estudos geográficos. Portanto, a Geografia de Gênero (ou Feminista), influenciada pela Geografia Cultural e Marxista, busca ao contrário do enfoque tradicional, integrar e dar visibilidade as mulheres e ressaltar que as relações 
A Utilização da Mídia Publicitária no Ensino de Geografia: Uma Oficina

\section{Pedagógica Acerca da Discriminação da Mulher}

de dominação e de subordinação do gênero feminino estão intrínsecas as lutas de classe. (REIS, 2015).

Para Reis (2015) incorporar as teorias de gênero nas análises geográficas permite que se relevem as manifestações espaciais e territoriais de diversos grupos sociais, que por meio de suas práticas constroem os espaços geográficos, “(...), pois o gênero é uma das relações estruturantes que situa o individuo no mundo." (REIS, 2015, p. 24). Assim, a Geografia Feminista busca investigar as relações entre as divisões de gênero e as divisões espaciais, para descobrir os problemas que estas divisões causam e que não muitas vezes ocultados e naturalizados.

Conforme Sampaio e França (2015), as relações de gênero podem ser entendidas como categorias de delimitações espaciais, e é necessário entender a participação da mulher na produção e reprodução do território e a espacialidade das lutas femininas e como a segregação espacial da mulher se torna violenta. "O controle moral que vem em conjunto com o papel determinado às mulheres num ambiente disciplinador repassado pela organização que reafirma a supremacia masculina é violenta. Um espaço que aprisiona as mulheres é violento." (SAMPAIO; FRANÇA, 2015, p. 63).

O espaço urbano se torna um lugar de aprisionamento feminino, pois o gênero se torna um importante elemento construtivo no ambiente urbano, pois estes espaços se tornam lugares de confinamento, constrangimentoe de barreiras invisíveis do patriarcado. Mesmo sendo uma figura importante na reprodução da força de trabalho no sistema capitalista, as mulheres ainda não são desvinculadas dos discursos moralistas e disciplinadores, que ao mesmo tempo em que exigem que as mesmas façam parte do sistema produtivo, as oprimem para que se comportem segundo os padrões socialmente estabelecidos. (SAMPAIO; FRANÇA, 2015).

Machado e Ratts (2017) ressaltam que homens e mulheres se apropriam dos espaços de formas distintas, pois elas sofrem restrições como as relacionadas ao sentimento de medo da violência física. "O medo sentido pelas mulheres ao transitarem nas ruas da cidade é também resultante de regulamentos sociais implícitos presentes nesse espaço." (MACHADO; RATTS, 2015, p. 197). As mulheres acabam sentindo um medo adicional, a qual os homens não temem com a mesma intensidade. Este medo não permite que as mulheres vivenciem certos lugares da cidade. Ruas em determinados locais e horários, espaços de confinamento, como as residências em periferias distantes, são elementos que se referem as diferenças de acesso físico de mulheres e homens a determinados espaços, e se consagram como barreiras invisíveis criadas pelo olhar opressivo de quem impõe ordem. (SILVA, 2003). É por isso que os movimentos feministas empoderam as mulheres a pensarem a importância de estarem ocupando espaços que até então não eram permitidos a elas ocuparem.

As discussões e análises sobre as questões de gênero se tornam assim, indispensáveis para que se possa compreender a discriminação da mulher, socialmente construída, aceita e reproduzida, e assim, buscar formas de lutas contra violência e opressão ao gênero feminino. 
A Utilização da Mídia Publicitária no Ensino de Geografia: Uma Oficina

Pedagógica Acerca da Discriminação da Mulher

O Uso da Publicidade como Recurso Didático no Ensino de Geografia

Segundo Nunes, (2001, p. 23 apud FARIAS, 2006, p. 1), a publicidade é “o ato comercial de índole coletiva, patrocinado por ente público ou privado, com ou sem personalidade, no âmbito de uma atividade econômica, com finalidade de promover, direta ou indiretamente, o consumo de produtos e serviços." A propaganda é assim, um importante meio de comunicação, pois atingem com facilidade quase todas as camadas sociais e auxiliam na reprodução de padrões e comportamentos sociais.

Os recursos audiovisuais, como as propagandas, podem auxiliar a potencializarão dos processos de ensino e aprendizagem, pois auxiliam na assimilação do conteúdo teórico, que pode ser muitas vezes massivo, e o transforma em algo prazeroso devido a mediação do professor. No entanto, é necessário que o educador aborde esses recursos de uma forma crítica e não apenas como um suporte para a transmissão de informações. (RUBERTI; PONTES, 2001)

Toda essa publicidade atinge a grande massa, muitas vezes por meio da televisão e da mídia em geral, e por esta razão segundo Freire (1996) é necessário debater o que se diz e o que se mostra neste meio, pois não basta apenas usá-la, mas, sobretudo, discuti-la. "É que pensar em televisão ou na mídia em geral nos põe o problema da comunicação, processo impossível de ser neutro." (FREIRE, 1996, p. 88). E por não ser neutro sempre será feito em favor de um ideal ou de alguém, que nem sempre é referido.

Por isto foram escolhidos para a aplicação da oficina em questão, como recursos didáticos iniciais dois vídeos comerciais na tentativa de construção de um pequeno debate crítico e de um levantamento prévio de ideias dos discentes sobre a representação da mulher na publicidade, a fim de que posteriormente se levantasse a questão da participação da mulher no processo de construção e apropriação espacial. O primeiro vídeo de uma famosa marca de cerveja retratava a campanha publicitária de 2014, onde a empresa divulgava uma promoção de até 50\% em sapatos femininos na hora da final da Champions League, para que as mulheres pudessem ser distraídas durante o jogo. O segundo comercial desenvolvido por uma marca de sabão em pó, questiona os papéis de gênero nas atividades domésticas. O comercial é narrado por um pai, que ao visitar sua filha já casada e com filhos, consegue então entender quão pesado é o fardo social imposto à mulher, pois além de trabalhar, ela também tem que cuidar sozinha da casa, do filho e do marido. $\mathrm{O}$ pai passa então a refletir sobre seus próprios erros, e lamenta não ter ensinado a filha que não era sua função ser a única responsável pelo lar, ao mesmo tempo em que faz uma autocrítica por não ter dado esse exemplo, já que nunca dividiu as tarefas domésticas com a sua esposa.

Diante da problemática exposta, o presente artigo tem como objetivo investigar por meio da oficina aplicada no Colégio Marcelino Champagnat nas três turmas do $3^{\circ}$ ano do ensino médio o que os discentes já pensavam sobre o assunto abordado e se conseguiram de alguma forma construir novas formas de enxergar a mulher nos processos de apropriação do espaço.

Na primeira parte da oficina buscou-se destacar como a discriminação da mulher está presente na sociedade por meio de uma pequena discussão inicial

Jéssica Justino Brandão, Ricardo Lopes Fonseca

Revista Latino-americana de Geografia e Gênero, Ponta Grossa, v. 10, n. 1, p. 181 - 196, jan. / jun. 2019. 
A Utilização da Mídia Publicitária no Ensino de Geografia: Uma Oficina

Pedagógica Acerca da Discriminação da Mulher

com a utilização de imagens e vídeos publicitários. Para que posteriormente se realizasse uma discussão e levantamento de ideias de como essa discriminação acaba resultando em diferentes formas de apropriação do espaço em relação aos gêneros.

\section{Procedimentos Metodológicos}

O presente artigo é um estudo dos resultados das oficinas realizadas no dia 10 de outubro de 2017, com três turmas do $3^{\circ}$ ano do Ensino Médio do Colégio Estadual Marcelino Champagnat. No total participaram das oficinas 85 alunos, sendo 24 alunos da turma $3^{\circ} \mathrm{A}, 30$ alunos da turma $3^{\circ} \mathrm{B}$ e 31 alunos da turma $3^{\circ} \mathrm{F}$. Dos 85 alunos, 33 eram do gênero masculino, 46 do gênero feminino e seis alunos não informaram seu gênero.

Foram utilizados como recursos didáticos na oficina, slides como apoio teórico, que possuíam algumas imagens publicitárias e também dois comercias para ajudar na discussão e levantamento de ideias junto aos alunos sobre a discriminação da mulher.

Inicialmente foram feitas algumas perguntas orais para os discentes servindo como um diagnóstico prévio para entender como os mesmos já compreendiam o assunto. Em seguida iniciou-se a exposição teórica do assunto, ressaltando dados estatísticos e notícias jornalísticas que comprovam a existência da discriminação de gênero, e ao mesmo tempo analisando como esses preconceitos e diferenças podem ser reforçadas com nossas pequenas atitudes cotidianas.

Para auxiliar a discussão do tema, foram utilizados dois vídeos publicitários. O primeiro vídeo refere-se a cerveja Heineken, onde a mesma vinculou uma campanha publicitária sobre a final da Liga dos Campeões da Europa (Champions League). Nesta campanha, denominada 'Heineken Shoe Sale', a marca visava que os homens pudessem assistir ao referido jogo sem a interferência de suas companheiras, e para isto, a marca lançou uma liquidação de sapatos femininos nas lojas da Shoestock na mesma hora da final da Liga dos Campeões. Desta forma, segundo a Heineken, as esposas ou namoradas, deixariam seus companheiros 'em paz'.

O segundo vídeo é um comercial divulgado na Índia e desenvolvido pela marca de sabão Ariel, que questiona os papéis de gênero nas atividades domésticas. O comercial é narrado por um pai, que ao visitar sua filha já casada e com filhos, consegue então entender quão pesado é o fardo social imposto à mulher, pois além de trabalhar, ela também tem que cuidar sozinha da casa, do filho e do marido. Após ver sua filha nesta situação, o pai passa a refletir sobre seus próprios erros, e lamenta não ter ensinado a filha que não era sua função ser a única responsável pelo lar, ao mesmo tempo em que faz uma autocrítica por não ter dado esse exemplo, já que nunca dividiu as tarefas domésticas com a sua esposa.

Após a exibição dos vídeos, fez-se a abertura para pequenos apontamentos dos alunos sobre os mesmos.

Em seguida iniciou-se uma discussão sobre como a discriminação do gênero feminino na sociedade produz diferentes formas de apropriação do espaço. Foram levantados problemas como: dificuldade de acesso a serviços 


\section{Pedagógica Acerca da Discriminação da Mulher}

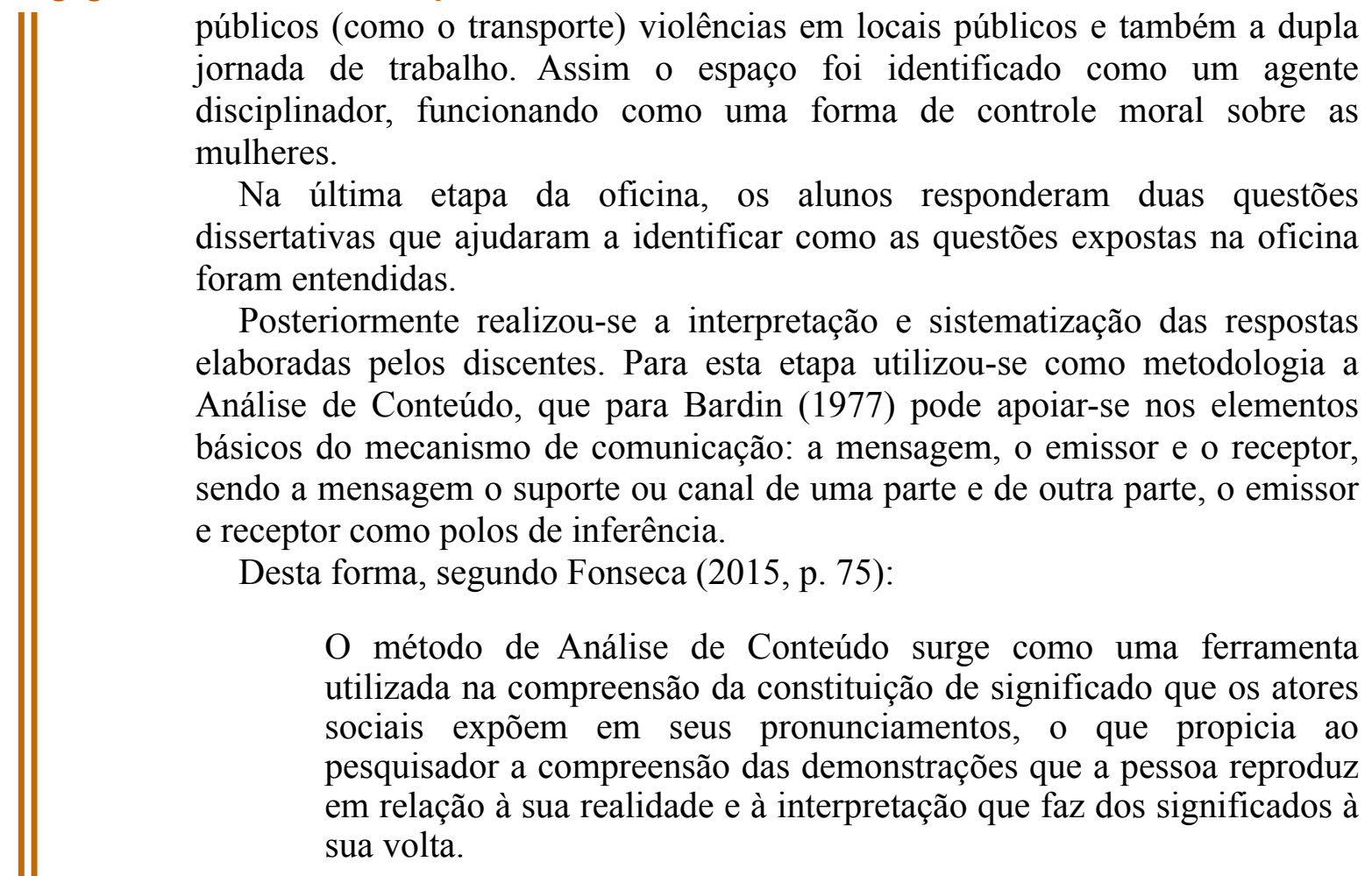

Desta forma, a presente pesquisa utilizará o modelo de categorização elaborado por Fonseca (2015, p. 96) baseado na Análise de Conteúdo de Bardin (1977) para a interpretação das respostas elaboradas pelos discentes.

Os três quadros elaborados para este artigo possuem: as categorias e a descrição das mesmas, as unidades de registros (UR), exemplos de verbalizações, a frequência relativa com que as verbalizações foram utilizadas pelos discentes, e o metatexto em que se discute os resultados obtidos com os quadros.

\section{Resultados Obtidos}

Após a exposição dos vídeos publicitários e da discussão com os discentes sobre a questão da discriminação de gênero, foram elaborados pelos mesmos as respostas escritas das duas seguintes perguntas:

1- "Após a exibição dos vídeos faça um pequeno comentário sobre os dois comerciais, comparando-os, refletindo sobre seus objetivos e diga se você concorda com ele(s) e se acredita que algum dos vídeos, ou os dois representam ou não uma realidade presente em nossa sociedade"

2- "Você acredita que existe uma discriminação do gênero feminino em nossa sociedade? Se sim, como essa discriminação influencia na produção do espaço? Alguns pontos que podem ser discutidos: divisão do trabalho, relações no mercado de trabalho, diferenças salariais, diferença na divisão dos afazeres domésticos, violência doméstica, mobilidade urbana e a representação da mulher nos comercias, revistas, filmes e novelas."

As respostas elaboradas pelos alunos serão discutidas nos quadros 01,02 e 03, por meio da categorização com base na Análise de Conteúdo.

O quadro 01 expressa a interpretação das respostas dos discentes, referente 
a questão 01. Por meio, das respostas foi possível constatar que a maioria dos discentes conseguiu emitir opiniões críticas quanto analise dos vídeos publicitários.

Quadro 01:Respostas da questão 01

CATEGORIA: Questão 1: Após a exibição dos vídeos faça um pequeno comentário sobre os dois comerciais, comparando-os, refletindo sobre seus objetivos e diga se você concorda com ele(s) e se acredita que algum dos vídeos, ou os dois representam ou não uma realidade presente em nossa sociedade.

O principal objetivo desta questão era que os discentes conseguissem expor comentários pessoais sobre o que entenderam e acharam dos dois vídeos publicitários exibidos, ressaltando se eles são um reflexo de nossa sociedade.

Em relação ao primeiro vídeo, da cerveja Heineken, o objetivo era entender como os discentes compreenderam a campanha publicitária. Por esta razão se esperava comentários críticos, onde os discentes exprimissem suas opiniões de concordância ou não com a proposta da campanha, ressaltando se acreditavam que a mesma teria um cunho machista ou não. Era esperado que os discentes conseguissem entender como a campanha publicitária em questão atribui de forma estereotipada papéis a serem desempenhados pelas mulheres e pelos homens na sociedade, e assim, contribuem de certa forma, com a reprodução desses padrões sociais.

Quanto ao segundo comercial, do sabão em pó Ariel, narrado por um pai que ao visitar sua filha já casada e com filhos, consegue compreender quão pesado é o fardo social imposto à mulher, pois além de trabalhar, ela também tem que cuidar sozinha da casa, do filho e do marido. O principal objetivo era que os discentes pudessem refletir como a situação expressada no vídeo ainda é muito comum em nossa sociedade, pois as mulheres ainda são as principais responsáveis pelos afazeres domésticos como confirma a pesquisa do Ipea de 2011, sobre o "Retrato das Desigualdades por gênero e por raça". Segundo o Ipea (2011), em 2009, apenas $49,1 \%$ dos homens e $88,2 \%$ das mulheres com mais de 10 anos declararam que cuidavam dos afazeres domésticos. Quanto a divisão do trabalho doméstico entre os sexos, percebeu-se, segundo o estudo, que desde os cinco anos de idade, são as meninas que recebem a atribuição dos afazeres domésticos, uma situação intensificada a partir dos 10 anos de idade e nas famílias com maior proporção de homens. Essas diferenças perduram ao longo da vida de homens e mulheres.

Assim, o objetivo desta questão era que os discentes pudessem associar a situação representada do vídeo com situações vivenciadas em seu cotidiano, e para isso utilizasse de comentários críticos e pudessem, além disso, analisar a postura do pai representado no segundo comercial como uma possibilidade de mudança na forma como os afazeres domésticos são atribuídos nas famílias.

\begin{tabular}{|l|l|c|}
\hline $\begin{array}{l}\text { UNIDADES DE } \\
\text { REGISTRO }\end{array}$ & EXEMPLOS DE VERBALIZAÇÃO & $\begin{array}{c}\text { FREQUÊNCIA } \\
\text { RELATIVA }\end{array}$ \\
\hline $\begin{array}{l}\text { UR1- } \\
\text { Comentário } \\
\text { crítico } \\
\text { relacionado aos } \\
\text { dois vídeos } \\
\text { publicitários }\end{array}$ & $\begin{array}{l}\text { Representam a realidade; Estereótipos } \\
\text { culturais; Machismo; Inferiorizar a mulher; } \\
\text { Dupla jornada de trabalho; Divisão desigual } \\
\text { dos afazeres domésticos; desigualdade de } \\
\text { gênero; Retratação da "superioridade } \\
\text { masculina"; Necessidade de mudanças } \\
\text { sociais; Visão patriarcal da sociedade; } \\
\text { Equidade de gêneros. }\end{array}$ & $74,1 \%$ \\
\hline
\end{tabular}




\begin{tabular}{|c|c|c|}
\hline $\begin{array}{l}\text { UR2- } \\
\text { Comentário } \\
\text { crítico de apenas } \\
\text { um dos vídeos } \\
\text { publicitários }\end{array}$ & $\begin{array}{l}\text { Conscientizar; Divisão dos trabalhos } \\
\text { domésticos; Representação da realidade; } \\
\text { Mulher como objeto. }\end{array}$ & $13 \%$ \\
\hline $\begin{array}{l}\text { UR3-Apenas } \\
\text { descrição dos } \\
\text { vídeos } \\
\text { publicitários }\end{array}$ & 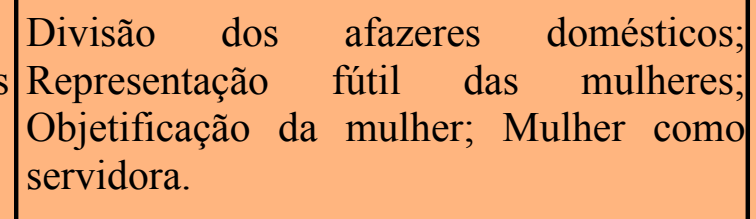 & $8,1 \%$ \\
\hline $\begin{array}{l}\text { UR4- } \\
\text { Fuga/ausência } \\
\text { de comentário } \\
\text { ou descrição dos } \\
\text { vídeos } \\
\text { publicitários }\end{array}$ & $\begin{array}{l}\text { Imposições sociais às mulheres; Divisão } \\
\text { dos afazeres domésticos. }\end{array}$ & $4,8 \%$ \\
\hline \multicolumn{3}{|c|}{ METATEXTO } \\
\hline \multicolumn{3}{|c|}{$\begin{array}{l}\text { Constatou-se que a maior parte dos educandos conseguiu expressar } \\
\text { comentários críticos em relação aos dois vídeos comerciais, sendo a maioria } \\
\text { deles, comentários que reconheciam o machismo e a discriminação de gênero } \\
\text { na sociedade, e projetaram em suas respostas opiniões contrárias a } \\
\text { desigualdades, estereótipos, a interiorização da mulher, a divisão desigual dos } \\
\text { afazeres domésticos, a visão patriarcal da sociedade e a representação } \\
\text { machista da mulher em campanhas publicitárias. } \\
\text { No entanto parte dos alunos esboçaram comentários críticos a apenas um } \\
\text { vídeo (13\%), ou não esboçaram comentários pessoais, realizando apenas uma } \\
\text { descrição do mesmo ( } 8 \% \text { ). Houve ainda uma pequena parcela dos alunos que } \\
\text { não se referiu aos comerciais em suas respostas (nem como comentário ou } \\
\text { mesmo como descrição), e um dos discentes não respondeu a primeira } \\
\text { questão. }\end{array}$} \\
\hline
\end{tabular}

Org.: Autores.

Desta forma, fica claro por meio do Quadro 01 que a maior parte dos discentes $(74,1 \%)$ conseguiu responder a primeira questão como o esperado, expressando suas opiniões sobre o assunto. No entanto, há que se destacar que as opiniões e comentários expressos quanto ao primeiro vídeo da cerveja Heineken foram bastante diversos, e por esta razão a presente pesquisa buscou elucidar por meio do Quadro 02 como os discentes interpretaram esta primeira campanha publicitária exibida, destacando aqueles que a entenderam como uma forma de discriminação; aqueles que não conseguiram identificar discriminação e alguns que não fizeram comentários pessoais sobre o primeiro vídeo publicitário, 
A Utilização da Mídia Publicitária no Ensino de Geografia: Uma Oficina

Pedagógica Acerca da Discriminação da Mulher

Quadro 02: Comentários e análises dos discentes sobre o comercial da cerveja Heineken

CATEGORIA: Comentários e análise dos discentes sobre o primeiro vídeo publicitário.

O primeiro comercial se refere a uma campanha publicitária da cerveja Heineken, sobre a final da Liga dos Campeões da Europa (Champions League). Com esta campanha a marca pretendia que seus consumidores do gênero masculino, pudessem assistir ao referido jogo sem a interferência de suas companheiras, e para isto, a marca lançou uma liquidação de sapatos femininos nas lojas da Shoestock na mesma hora da final da Liga dos Campeões. Desta forma, segundo a Heineken, as esposas ou namoradas, deixariam seus companheiros "em paz" durante a exibição da partida.

Busca-se com este comercial levantar a discussão de como os estereótipos sociais referentes ao gênero, enraizados em nossa sociedade continuam sendo reproduzidos nos meios de comunicação, e assim auxiliando a continuação da discriminação e da mulher.

\begin{tabular}{|c|c|c|}
\hline $\begin{array}{l}\text { UNIDADES DE } \\
\text { REGISTRO }\end{array}$ & EXEMPLOS DE VERBALIZAÇÃO & $\begin{array}{c}\text { FREQUÊNCIA } \\
\text { RELATIVA }\end{array}$ \\
\hline $\begin{array}{l}\text { UR1- } \\
\text { Identificação de } \\
\text { discriminação no } \\
\text { primeiro vídeo } \\
\text { publicitário }\end{array}$ & $\begin{array}{l}\text { Determinação cultural de atividades de } \\
\text { cada gênero; Machismo; Desigualdade de } \\
\text { gênero; Retratação da "superioridade" } \\
\text { masculina; Desrespeito com as mulheres; } \\
\text { Piada de mau gosto; Sociedade patriarcal; } \\
\text { Reflexão sobre o papel das mulheres na } \\
\text { sociedade. }\end{array}$ & $69,4 \%$ \\
\hline $\begin{array}{l}\text { UR2- Não } \\
\text { identificação de } \\
\text { discriminação no } \\
\text { primeiro vídeo } \\
\text { publicitário }\end{array}$ & $\begin{array}{l}\text { Publicidade para atrair novos } \\
\text { compradores; Nada demais; Baseado na } \\
\text { maioria; Segue o estereótipo; Não é } \\
\text { machista; O objetivo é apenas satisfazer } \\
\text { tanto o homem quanto a mulher; Não } \\
\text { apresenta discriminação; Toda mulher } \\
\text { prefere ir comprar sapatos que assistir a } \\
\text { um jogo. }\end{array}$ & $9,4 \%$ \\
\hline $\begin{array}{l}\text { UR3- Não } \\
\text { fizeram } \\
\text { comentários } \\
\text { pessoais sobre o } \\
\text { primeiro vídeo } \\
\text { publicitário }\end{array}$ & & $21,2 \%$ \\
\hline
\end{tabular}

METATEXTO

A maioria dos educandos conseguiu identificar a discriminação de gênero no primeiro comercial e emitir opiniões críticas sobre o mesmo, ressaltando, por exemplo, como os estereótipos são criados culturalmente; como a presença do machismo e a crença na "superioridade masculina" são presentes em nossa sociedade. Evidenciaram ainda que acreditam que o comercial foi uma piada de mau gosto e que auxilia na reprodução de uma sociedade patriarcal, onde o papel das mulheres é visto como inferior ao dos homens.

No entanto, foi registrado um percentual considerável $(21,2 \%)$ de alunos que não 
emitiram comentários pessoais sobre o primeiro comercial e uma parcela de alunos $(9,4 \%)$ que não identificaram a presença da discriminação de gênero no referido comercial. Segundo esses alunos o vídeo publicitário em questão serve apenas para atrair novos compradores; é baseado na maioria, pois a maior parte das mulheres prefere comprar sapatos a assistir um jogo de futebol. Outros alunos ressaltaram que em suas opiniões o objetivo da marca era apenas satisfazer os interesses dos dois gêneros.

Um fato interessante, é que dos $9,4 \%$ que disseram não haver a presença da discriminação de gênero no comercial, $5,9 \%$ são do gênero masculino, $2,4 \%$ do gênero feminino e $1,1 \%$ não declararam seu gênero. Ou seja, a maior parte daqueles que não identificaram tal discriminação não possuíam o "lugar de fala" no caso deste tipo de discriminação.

Em relação aos discentes que conseguiram identificar a discriminação $40 \%$ dos $69,4 \%$ eram do gênero feminino, $25,9 \%$ do gênero masculino e $3,5 \%$ não declararam seu gênero. Assim, fica evidenciado como as próprias discentes em seu "lugar de fala" conseguiram identificar com maior facilidade a discriminação presente no vídeo.

Desta forma, observa-se que mesmo após a discussão em sala, uma parte dos alunos ainda possuem dificuldades para conseguir identificar e reconhecer a discriminação da mulher, que muitas vezes encontra-se mascarada nos pequenos gestos e atitudes.

Org.: Autores.

O quadro 02 reflete a necessidade dos educadores buscarem construir junto aos discentes um olhar crítico quanto as diversas manifestações de discriminação na sociedade, e desta maneira contribuir para que os educandos compreendam que nossas atitudes, mesmo não parecendo, podem e continuam auxiliando a permanência de uma sociedade preconceituosa.

Quadro 03:Respostas da questão 02

CATEGORIA: Questão 2: Você acredita que existe uma discriminação do gênero feminino em nossa sociedade? Se sim, como essa discriminação influencia na produção do espaço?

Para a Geografia Feminista as divisões de gênero influenciam a forma como o espaço é produzido e apropriado. Muitos espaços servem de confinamentos, barreiras invisíveis do patriarcado, e a mulher mesmo tendo se tornado uma figura importante como força de trabalho no sistema capitalista, ainda é alvo de discursos moralistas que as obriga a seguir padrões socialmente estabelecidos.

Desta forma a segunda questão aplicada aos discentes foi elaborada para buscar compreender se os mesmos acreditam que existe a discriminação da mulher e também se conseguiram associar o tema da aula com aspectos geográficos, relacionados principalmente a produção do espaço.

\begin{tabular}{|c|c|c|}
\hline $\begin{array}{c}\text { UNIDADES DE } \\
\text { REGISTRO }\end{array}$ & EXEMPLOS DE VERBALIZAÇÃO & $\begin{array}{c}\text { FREQUÊNCIA } \\
\text { RELATIVA }\end{array}$ \\
\hline $\begin{array}{lr}\text { UR1-Comentário } \\
\text { sobre } & \text { a } \\
\text { influência } & \text { da } \\
\text { discriminação } & \text { na } \\
\text { produção } & \text { do } \\
\text { espaço } & \end{array}$ & $\begin{array}{l}\text { Desigualdade no espaço doméstico; } \\
\text { Violência urbana; Segregação feminina; } \\
\text { Maior dificuldade de acesso a espaços } \\
\text { públicos; Divisão do trabalho por gênero; } \\
\text { Efeitos da discriminação no espaço; Medo } \\
\text { do assédio. }\end{array}$ & $32,9 \%$ \\
\hline
\end{tabular}


Pedagógica Acerca da Discriminação da Mulher

\begin{tabular}{|c|c|c|}
\hline $\begin{array}{lr}\text { UR2- } & \text { Sem } \\
\text { comentários } & \\
\text { sobre } & \mathrm{a} \\
\text { influência } & \mathrm{da} \\
\text { discriminação } & \text { na } \\
\text { produção } & \text { do } \\
\text { espaço } & \end{array}$ & $\begin{array}{l}\text { Discriminação da mulher; Machismo; } \\
\text { Diferenças salariais; Dificuldade na } \\
\text { inserção no mercado de trabalho; Vista } \\
\text { como empregada; Representação da } \\
\text { mulher na publicidade; Submissas; } \\
\text { Violência doméstica; Vantagens } \\
\text { masculinas; Preconceito; Representação } \\
\text { da mulher nos meios de comunicação. }\end{array}$ & $63,5 \%$ \\
\hline $\begin{array}{l}\text { UR3- Não } \\
\text { acreditam que } \\
\text { haja } \\
\text { discriminação ou } \\
\text { não possuem } \\
\text { opinião definida } \\
\text { sobre o assunto }\end{array}$ & $\begin{array}{l}\text { Nunca presenciou discriminação; Não há } \\
\text { discriminação; Não é possível haver } \\
\text { igualdade; Não somos iguais; Apenas } \\
\text { falhas na execução das leis. }\end{array}$ & $3,6 \%$ \\
\hline \multicolumn{3}{|c|}{ METATEXTO } \\
\hline
\end{tabular}

Foi verificado que os educandos tiveram dificuldade para conseguir associar o tema da oficina com aspectos geográficos relacionados a produção do espaço, mesmo que a discussão sobre esse assunto tenha sido efetuada durante o decorrer da oficina. Muitos citaram a questão da desigualdade salarial, do machismo, da forma como as mulheres são representadas em vídeos publicitários, dos preconceitos sofridos por elas, mas, no entanto, não conseguiram fazer nenhum tipo de associação quanto a produção espacial.

Apenas 32,9\% dos discentes apontaram aspectos que evidenciavam a influência da discriminação na produção espacial como, por exemplo, a segregação feminina em espaços públicos, a violência urbana gerada pelo assédio, e o consequente medo e insegurança sentida. Além disso, foram citados problemas como a maior dificuldade de acesso da mulher a espaços públicos, a divisão do trabalho pelo gênero e como isso influencia na espacialização do homem e da mulher nos espaços sociais. Esse cenário de grande dificuldade a associar aspectos geográficos nas respostas dos discentes pode representar uma falha no processo de construção do processo de ensino e aprendizagem do objeto da geografia.

Uma pequena parcela dos alunos (3,6\%, o que representa 3 dos 85 discentes) não acreditam que exista discriminação da mulher na sociedade. Um deles apontou que acredita não ser possível haver a igualdade, pois não somos iguais, outro acredita que não há discriminação, apenas uma falha na execução das leis, o que segundo o mesmo, poderia ser resolvido com a legalização do porte de armas. A partir destes discursos, é possível perceber como alguns dos discentes além de não acreditarem na discriminação e não conseguir associá-la a produção do espaço possuem um discurso machista e discriminatório.

O fato de a maior parte dos alunos não ter conseguido associar a discriminação da mulher com a produção espacial e também não acreditarem na discriminação de gênero, é uma importante evidência de como o professor de Geografia deve trabalhar questões sociais e associá-las ao espaço geográfico, e como as mesmas interferem, produzem e são reproduzidas constantemente.

Org.: Autores.

Jéssica Justino Brandão, Ricardo Lopes Fonseca 
A Utilização da Mídia Publicitária no Ensino de Geografia: Uma Oficina

Pedagógica Acerca da Discriminação da Mulher

Por meio das análises dos quadros 01,02 e 03, confirma-se a importância de tornar evidente aos educandos a discriminação sofrida pela mulher. Desta maneira, o professor de Geografia deve realizar durante suas práticas educativas a associação dos problemas e fatos sociais com o espaço geográfico, mostrando aos discentes como estes interferem na produção e reprodução de estereótipos que consequentemente contribuirão para determinadas formas de organização espacial.

\section{Considerações Finais}

O preconceito e a discriminação ainda é um grande desafio enfrentado pelas mulheres constantemente. Mesmo possuindo o direito a cidadania e a liberdade, elas ainda encontram a necessidade de buscarem que os mesmos sejam cumpridos e que o seu direito aos espaços na sociedade sejam respeitados.

Por esta razão faz-se necessário que os educadores, em seu exercício de problematizar e mediar os conhecimentos consigam evidenciar como a discriminação da mulher interfere diretamente na organização da sociedade.

O presente artigo buscou, por meio de vídeos publicitários, levantar uma discussão com discentes do ensino médio, sobre como a mulher é vista e tratada na sociedade. Desta maneira, observou-se durante a realização das oficinas que os comerciais foram de grande auxilio para conseguir introduzir o assunto em questão e ao mesmo tempo, instigar os discentes a realização da discussão e produção das respostas do questionário. Buscou-se ainda durante a oficina desenvolver a problemática da apropriação espacial dos gêneros, ou seja, como a desigualdade de gêneros e a discriminação faz com que homens e mulheres se apropriem de espaços diferentes, e de formas diferentes.

Desta maneira, foi possível observar que a maioria dos discentes compreendem que existe uma discriminação do gênero feminino na sociedade, e que este problema pode ser refletido, por exemplo, nos vídeos publicitários. No entanto, notou-se também que a maior parte dos discentes não conseguiu na resposta da questão 02 , fazer a associação da discriminação da mulher com produção e reprodução espacial, o que nos indica uma dificuldade dos mesmos em fazer a associação do tema em específico com os aspectos geográficos, e talvez uma deficiência dos alunos em compreender o objeto; o objetivo e suas principais categorias da geografia.

Durante a realização das oficinas, a recepção dos alunos perante o assunto exposto foi receptiva em sua grande maioria, apenas dois alunos manifestaram posições preconceituosas e de repreensão quanto à temática trabalhada. Assim, mesmo que grande parte dos alunos tenham se mostrado abertos ao diálogo e compreensíveis a discussão exposta, os poucos alunos que se manifestaram contrários, refletem a necessidade e importância de se realizar discussões e análises junto aos discentes sobre os preconceitos, a discriminação, as injustiças e as suas diversas formas de reprodução social e espacial, e para que desta maneira seja possível construir conjuntamente novas formas de enxergar o papel das mulheres na sociedade. 
A Utilização da Mídia Publicitária no Ensino de Geografia: Uma Oficina

Pedagógica Acerca da Discriminação da Mulher

\section{Referências}

BARDIN, L. L'analyse de contenu. $8^{\text {a }}$ édition corrigée. Paris: Presses Universitaires de France, 1977.

FARIAS, T. Q. Publicidade e propaganda no Código de Defesa do

Consumidor. Âmbito Jurídico, v. 9, n. 28, 2006. Disponível em: $<$ http://www.ambitojuridico.com.br/site/index.php?n_link=revista_artigos_leit ura\&artigo_id=1082>. Acesso em 29 de Outubro. De 2017.

FONSECA, R. L. Avaliação da preparação de graduandos de Geografia para a inclusão de alunos com necessidades educacionais especiais. 2015. Tese (Doutorado em Geografia) - Universidade Estadual de Londrina, Londrina.

FREIRE, P. Pedagogia da autonomia: saberes necessários à prática educativa. 7. ed. Rio de Janeiro: Paz e Terra, 1996.

IPEA. Uso do tempo. Retratos das desigualdades por gênero e por raça. $4^{\mathrm{a}}$ ed. Brasília: Ipea, 2011.

MACHADO, T. C.; RATTS, A. J. P. As Mulheres e a Rua: Entre o Medo e as Apropriações Feministas da Cidade de Goiânia, Goiás. Revista Latino Americana de Geografia e Gênero, v. 8, n. 1, p. 194 - 213, 2017.

MOREIRA, R. Pensar e ser em Geografia: ensaios de historia, epistemologia e ontologia do espaço geográfico. São Paulo: Contexto, 2015.

REIS, M. L. Estudos de Gênero na Geografia: Uma Análise Feminista da Produção do Espaço. Espaço e Cultura, v. 38, n. 1, p. 11 - 34, 2015.

RUBERTI, I.; PONTES, A. N. Mídia, educação e cidadania: considerações sobre a importância da alfabetização tecnológica audiovisual na sociedade da informação. Disponível em: $<$ httpwww.iar.unicamp.brlabluzldLinguagem\%20Visualmidia_educacao_e_cid adania_h>. Acesso em 29 de Outubro de 2017.

SAMPAIO, L; FRANÇA, L. As relações de gênero aplicadas à analise socioespacial: como a construção cultural no espaço urbano aprisiona as mulheres. In: $2^{\circ}$ WORKSHOP DE GEOGRAFIA CULTURAL, n.2, 2015, Alfenas. Anais... p. 59-70.

SILVA, J. M. Geografias Feministas, Sexualidades e Corporalidades: Desafios às Práticas Investigativas da Ciência Geográfica. Espaço e Cultura, v. 27, n. 1, p. $39-55,2010$.

SILVA, J. M. Um ensaio sobre as potencialidades do uso do conceito de gênero 
A Utilização da Mídia Publicitária no Ensino de Geografia: Uma Oficina

Pedagógica Acerca da Discriminação da Mulher

na análise geográfica. Revista de História Regional, v. 8, n. 1, p. 31 - 45, 2003.

SILVA, S. M. V. da. Geografia e Gênero/Geografia Feminista. O Que é Isto?. Boletim Gaúcho de Geografia, v. 23, n. 1, p. 105 - 110, 1998.

\section{Recebido em 12 de abril de 2018. \\ Aceito em 08 de setembro de 2018.}

Jéssica Justino Brandão, Ricardo Lopes Fonseca 